\title{
Diferenças Individuais na Aquisição de Leitura com um Sistema Lingüístico em Miniatura ${ }^{1}$
}

\author{
Elenice S. Hanna ${ }^{2}$ \\ Marina Kohlsdorf, \\ Regiane S. Quinteiro \\ Virgínia M. D. Fava \\ Universidade de Brasília \\ Deisy das Graças de Souza \\ Júlio C. de Rose \\ Universidade Federal de São Carlos
}

\begin{abstract}
RESUMO - Este estudo relata o emprego de um sistema lingüístico em miniatura para investigar a aprendizagem de leitura. Vinte estudantes de graduação (10 da área de exatas e 10 de humanas) aprenderam a relacionar figuras e pseudo-palavras impressas às correspondentes pseudo-palavras ditadas, em tarefas de discriminação condicional realizadas em computador. Sessões de ensino foram intercaladas com testes de leitura de palavras novas, formadas pela recombinação de elementos das palavras ensinadas (generalização recombinativa). Nove estudantes de exatas e quatro de humanas apresentaram leitura recombinativa após a aprendizagem de 12 palavras. Os escores em leitura de palavras novas aumentaram à medida que aumentava o número de palavras ensinadas. Ambos os achados podem ser interpretados como efeitos de experiências de aprendizagem com relações simbólicas. As diferenças entre estudantes das áreas de humanas e exatas podem também refletir fatores motivacionais.
\end{abstract}

Palavras-chave: aprendizagem de leitura; sistema lingüístico em miniatura; quantidade de treino; ciências exatas e humanas; universitários.

\section{Individual Differences in Reading Acquisition with a Miniature Linguistic System}

\begin{abstract}
This study reports the use of a miniature linguistic system in order to investigate reading acquisition. Twenty college students, 10 from Natural Sciences and Engineering (NSE) and 10 from Health and Social Sciences (HSS) courses, learned to relate pictures and printed pseudo-words to dictated pseudo-words in conditional discrimination tasks presented by a computer. Teaching sessions were interspersed with tests of reading new words formed by recombination of elements of taught words (generative recombination). Nine students from NSE and four from HSS developed generalized reading after learning 12 relations with pseudo-words. Reading scores of new words increased as number of taught words increased. Both findings could be interpreted as effects of learning experiences with symbolic relations. Differences between the NSE and the HSS students could also reflect motivational factors.
\end{abstract}

Key words: reading; miniature linguistic system; amount of training; health and social sciences; natural sciences and engineering; college students.

Um Sistema Lingüístico em Miniatura (Esper, 1925, 1933) consiste de um conjunto de estímulos que variam ao longo de uma ou mais dimensões (e.g., forma, letra, posição) e um conjunto de respostas específicas a serem emitidas na presença daqueles estímulos (Foss, 1968). Sistemas lingüísticos naturais variam em muitas dimensões, como o grau de correspondência entre diferentes estímulos e respostas, o número de elementos e de regras subjacentes ao sistema.

1 Manuscrito redigido durante licença sabática como professor visitante da primeira autora na Universidade Federal de São Carlos (auxílio FAPESP $n^{\circ}$. 05/56502-8). Projeto apoiado pelo CNPq (PQ processo $n^{\circ}$. 305590/2004-9) e FINATEC. Agradecemos aos alunos que colaboraram na coleta de dados: Adriana Pinheiro Carvalho, Camila Akemi, Cinthia Camimura, Fernanda Trancoso de Morais, Licio Andrade, Lilian Cherulli de Carvalho, Luciano Oliveira, Patrícia Serejo de Jesus, Roberta Ladislau, Talita Leão e Thiago Cardoso Costa.

2 Endereço: SQN 106, Bloco I, apto 306, Brasília, DF, Brasil 70.742-090. E-mail: hanna@unb.br
Sistemas lingüísticos em miniatura (SLM) têm sido úteis e valiosos para analisar relações funcionais entre variáveis ambientais e desenvolvimento de linguagem (Foss, 1968; Goldstein, 1981, 1983; Horowitz \& Jackson, 1959; Kennedy, 1972; MacWhinney, 1983; Miller \& Ames, 1972; Nation \& McLaughlin, 1986; Negata, 1977; Wetherby, 1978), possibilitando a manipulação e o controle das características do sistema inventado. O SLM inventado tem a vantagem adicional importante de possibilitar o controle da história com os estímulos, por exemplo, letras e pseudo-palavras.

Um sistema com letras inventadas como estímulos, aos quais devem ser emitidas respostas orais, com correspondência entre fonemas e letras, é útil no estudo sobre aquisição de leitura e de comportamento textual (Skinner, 1957), definido como uma resposta verbal sob um controle preciso, ponto a ponto, de um estímulo textual (o texto geralmente é impresso, visual, mas poderia ser em relevo, como em Braille; a resposta geralmente é vocal, mas também poderia ser gestual, como 
na Língua de Sinais; o ponto central é a relação de controle discriminativo entre o texto e a resposta verbal).

Estudos recentes com um SLM inventado foram realizados com crianças para estudar a aquisição de leitura (Albuquerque, 2001; Hanna, Albuquerque, Quinteiro \& Kohlsdorf, 2004; Rocha, 1996). Os resultados replicaram parcialmente aqueles obtidos com sistemas lingüísticos naturais e que empregaram procedimentos de ensino semelhantes (e.g., de Rose, de Souza \& Hanna, 1996; Hübner, Matos \& Serra, 2002; Matos, Avanzi \& McIlvane, 2006; Matos, Hübner \& Peres, 1997, 1999; Mueller, Olmi \& Saunders, 2000; Saunders, O’Donnell, Vaidya \& Williams, 2003): as crianças aprenderam rapidamente a relacionar figuras a palavras ditadas e a relacionar palavras impressas às mesmas palavras ditadas; aprenderam, também, a ler oralmente as palavras. Porém, a leitura de palavras novas, formadas pela recombinação de elementos textuais de palavras ensinadas, que é um teste crítico em estudos com sistemas lingüísticos naturais, foi incipiente e apresentou muita variabilidade entre aprendizes.

Levar o aluno a ler textos novos, não ensinados diretamente, é, no entanto, o objetivo principal de um alfabetizador e, por essa razão, é fundamental reproduzir e estudar o processo com um SLM inventado. Essa habilidade requer que o leitor identifique a ocorrência de novas combinações dos elementos de texto (letras, sílabas, palavras ou frases) já aprendidos e recombine as respostas sob controle desses elementos.

O desempenho novo, que tem origem na recombinação de estímulos e de respostas previamente aprendidas, é denominado generalização recombinativa (Alessi, 1987; Goldstein, 1981, 1983; Skinner, 1957). A leitura recombinativa é um desempenho emergente complexo que envolve discriminações e abstrações de sons e textos (Alessi, 1987), a formação de relações entre esses elementos, a identificação de elementos em diferentes contextos e posições e a emissão de novas sequiências de respostas sob controle de novos estímulos compostos por elementos daqueles previamente ensinados. $\mathrm{O}$ desenvolvimento de leitura recombinativa tem sido documentado com diversos procedimentos de ensino (e.g., Adams, 1994; de Rose \& cols., 1996; de Souza, de Rose, Fonseca \& Hanna, 1999; Matos \& cols., 1997, 1999, Matos \& cols., 2006; Mueller \& cols., 2000), mas uma característica geral dos achados é uma grande variabilidade entre participantes individuais.

Os estudos que ensinaram o participante a relacionar palavras ditadas, palavras impressas e figuras (de Rose \& cols., 1996; de Souza \& cols., 1999; Hübner \& cols., 2002; Matos \& cols., 1997, 1999, Matos \& cols., 2006; Mueller \& cols., 2000) empregaram o procedimento de pareamento ao modelo (Cumming \& Berryman, 1965) para ensinar as relações entre estímulos; a leitura não era ensinada diretamente, mas desenvolveu-se como subproduto das tarefas de seleção. Sob essas condições, as crianças aprenderam as relações diretamente ensinadas (selecionar uma entre várias figuras, quando a palavra correspondente é ditada e selecionar uma entre várias palavras impressas sob controle de uma palavra ditada) e foram capazes, também, de nomear (ler) corretamente as palavras impressas, quando apresentadas individualmente, além de relacionar diretamente figuras a palavras e vice-versa (e.g.de Rose \& cols., 1996; Matos \& cols., 1997, 1999, Matos \& cols., 2006; Melchiori, de Souza \& de Rose, 2000). Esses desempenhos emergentes têm sido considerados como evidências de que os estímulos empregados nas diferentes relações de controle estabelecidas pelo procedimento de ensino passam a formar uma classe de equivalência (de Rose, 1993; Sidman, 1994; Sidman \& Tailby, 1982). Em classes de equivalência, as relações entre os membros são definidas pelas propriedades de reflexividade, simetria e transitividade; quando os membros de uma classe são estímulos como palavras (faladas e impressas) e seus referentes, a demonstração de equivalência permite inferir que os estímulos compartilham funções simbólicas, isto é, as palavras passam a funcionar como símbolos dos referentes.

Nesses estudos, portanto, o emprego do procedimento de pareamento com o modelo e a estratégia de ensinar desempenhos inter-relacionados têm sido importantes para gerar não apenas o comportamento textual mas também a leitura com compreensão (de Rose \& cols., 1996; Hübner \& cols., 2002; Matos \& cols., 1997, 1999, Matos \& cols., 2006; Melchiori $\&$ cols., 2000). No entanto, como em outros estudos, os testes de leitura recombinativa mostraram resultados muito variados: enquanto alguns alunos liam um amplo conjunto de palavras novas, outros liam poucas ou nenhuma palavra. Variabilidade individual é comum em desempenhos emergentes complexos, mas sua interpretação no caso de estudos com sistemas naturais é dificultada pela ausência de controle de diversas variáveis. Em primeiro lugar, nesses estudos, o ensino de palavra inteira deixa ao acaso as correspondências que o aluno estabelece entre unidades menores de sons e texto (de Rose \& cols., 1996; Sidman, 1994). Além disso, na língua portuguesa, por exemplo, as correspondências entre letras e fonemas não são unívocas e dependem de letras adjacentes. A vogal " $e$ " (e outras) pode ser pronunciada de forma aberta (como em café), fechada (como em medo) ou nasalizada (como em lenta). Se o estudo é conduzido com crianças que se encontram em fase de alfabetização no ensino formal, os resultados podem sofrer interferência de efeito adicional e interativo de procedimentos e conteúdos utilizados pela escola, especialmente se nos dois contextos, experimental e escolar, for enfatizado o estabelecimento de relações entre letras e seus respectivos fonemas. Dessa perspectiva, o emprego de um SLM inventado pode ser vantajoso, por possibilitar o controle de diversos tipos de variáveis, incluindo os da história prévia de aprendizagens dos participantes de pesquisa.

Este estudo relata a metodologia desenvolvida para investigar a aquisição de relações simbólicas que constituem a leitura (algumas diretamente ensinadas e outras emergentes) e mostra como o SLM pode auxiliar a identificar variáveis de controle importantes. Foi especificamente investigado o efeito da quantidade de palavras ensinadas. Estudos prévios levantaram a possibilidade de que a emergência de leitura recombinativa pode depender da quantidade de palavras aprendidas; no entanto, eles envolviam a manipulação de outros fatores que dificultaram afirmações conclusivas. $\mathrm{Na}$ maioria dos estudos com palavras da língua portuguesa (e.g., de Rose \& cols., 1996; Melchiori \& cols., 2000), o aumento do número de palavras ensinadas era acompanhado pelo aumento concomitante no número de letras e fonemas empregados; além disso, não foi garantida uma correspondência unívoca entre letras e fonemas (por exemplo, uma mesma vogal podia ser aberta em uma palavra e fechada em outra). Em estudos com pseudo-alfabeto (Albuquerque, 2001; Hanna 
\& cols. 2004; Rocha, 1996) foram relatados progressos na aprendizagem de leitura que parecem ter resultado da quantidade de palavras que foram ensinadas de forma cumulativa, mas a manipulação concomitante de outras variáveis também não permitiu afirmações conclusivas a esse respeito.

O presente estudo realizou uma replicação sistemática de uma das condições do estudo de Albuquerque (2001), visando avaliar, com um sistema lingüístico em miniatura, o efeito da quantidade de palavras ensinadas sobre a emergência da leitura recombinativa. Os participantes foram adultos universitários, o que permitiu controlar a variável alfabetização; assim, os participantes tinham apenas que aprender as novas relações entre os grafemas e fonemas das palavras, de acordo com o alfabeto inventado. O emprego de pseudo-palavras permitiu controlar possíveis diferenças individuais com relação à história prévia de aprendizagem de palavras da língua portuguesa e seus significados. Um objetivo adicional do estudo consistiu em verificar se a área do curso de graduação (humanidades ou ciências exatas) dos estudantes afetaria o grau e a velocidade do desenvolvimento de leitura recombinativa.

O procedimento geral de ensino consistiu em ensinar relações de correspondência entre palavras ditadas e palavras impressas, e entre as mesmas palavras ditadas e figuras abstratas. Essa estratégia de ensino, que incluiu também o ensino de relações entre palavras ditadas e figuras correspondentes, permitiu não só testes de leitura oral de palavras mas também os testes de formação de classes de equivalência (Sidman, 1994), como avaliações adicionais de leitura funcional que requer a compreensão do símbolo textual.

\section{Método}

\section{Participantes}

Participaram do estudo 10 estudantes universitários de cursos da área de exatas e 10 da área de humanidades da Universidade de Brasília, conforme categorização utilizada pela universidade. A Tabela 1 mostra a idade, sexo e cursos dos participantes de cada área. Os participantes eram voluntários da disciplina de Introdução à Psicologia que tinham disponibilidade de dois ou mais horários de $30 \mathrm{~min}$ por semana para realizar as sessões experimentais. Eles foram informados que poderiam desistir de participar do estudo a qualquer momento. O tempo de participação no estudo foi convertido em pontos extra, ao final do semestre, para os estudantes já aprovados na disciplina (máximo de 5 pontos em 100). Antes do estudo, o participante lia e assinava um termo de consentimento esclarecido que informava: que o estudo era sobre aprendizagem simbólica; o número aproximado de sessões; a natureza da tarefa a ser realizada; sobre a possibilidade de converter o tempo de participação em pontos extra; e que os resultados poderiam ser divulgados mantendo-se o sigilo sobre a identidade do participante.

\section{Local, Equipamento e Material}

As sessões eram realizadas em uma sala de aproximadamente 2,30m x 3,70m devidamente preparada para a coleta de dados, localizada no Anexo do Laboratório de Aprendizagem Humana do Instituto de Psicologia da Universidade de Brasília. Em todas as sessões estavam presentes duas pessoas treinadas para operar os equipamentos e registrar as respostas orais. O programa MTS v. 11.6.7, desenvolvido por William Dube e Eric Hiris, do Shriver Center for Mental Retardation, Waltham, Massachussets (Dube, 1991), era executado em um computador Macintosh Performa 6230CD. O computador programava as contingências, apresentava as tentativas e instruções de cada etapa e realizava os registros das escolhas dos estímulos realizadas pelos participantes. Protocolos de registro, um gravador e fitas K7 foram utilizados para registro de respostas orais.

\section{Estímulos}

Para conveniência na descrição, os conjuntos de estímulos foram denominados pelas letras A, B e C. Palavras faladas (A) eram apresentadas em caixas de som acopladas ao computador. Palavras escritas (C) e/ou desenhos ambíguos (B) eram apresentados em uma ou mais de quatro janelas de $3 \mathrm{~cm}$ x $3 \mathrm{~cm}$ ativas na tela do monitor (ver Figura 1, Quadro $a$ ). As palavras faladas (A) foram gravadas em voz feminina e masculina e eram todas dissílabas do tipo consoante-vogalconsoante-vogal (CVCV), pronunciadas como oxítonas com as vogais abertas. As palavras impressas (C) eram escritas com as letras de um alfabeto inventado que se assemelhavam às letras gregas (ver exemplos na Tabela 2) e tinham correspondência unívoca com letras do alfabeto português e com fonemas da língua portuguesa. As palavras utilizadas em sessões de treino eram as 12 combinações possíveis de duas das sílabas NI, BO, LE e FA, ou seja: NIBO, NILE, NIFA, BONI, BOLE, BOFA, LENI, LEBO, LEFA, FANI, FABO e FALE. Para sessões de teste foram criadas 14 palavras, também dissílabas oxítonas com a estrutura CVCV, formadas pela recombinação das letras das palavras de treino (ex: NIBE, LOFI), sem repetição de letras.

Tabela 1. Características dos participantes de cada área de concentração.

\begin{tabular}{|c|c|c|c|c|c|c|c|}
\hline Exatas & & & & Humanidades & & & \\
\hline Participte. & Sexo & Idade & Curso & Participte. & Sexo & Idade & Curso \\
\hline FREDO & M & 19 & Geologia & JMAR & $\mathrm{M}$ & 18 & Filosofia \\
\hline MAN & M & 20 & Eng. Redes & VIC & M & 18 & Administração \\
\hline DIDI & M & 20 & Eng. Civil & PED & M & 20 & Comun. Social \\
\hline CACA & M & 21 & Eng. Redes & SAN & M & 22 & Artes Plásticas \\
\hline $\mathrm{CACO}$ & M & 21 & Eng. Redes & DIE & M & 22 & Comun. Social \\
\hline TIM & M & 23 & Computação & CIN & $\mathrm{F}$ & 18 & Nutrição \\
\hline CRI & $\mathrm{F}$ & 21 & Eng. Civil & LARA & $\mathrm{F}$ & 19 & Nutrição \\
\hline ARA & $\mathrm{F}$ & 21 & Eng. Civil & ISA & $\mathrm{F}$ & 19 & Enfermagem \\
\hline FER & $\mathrm{F}$ & 23 & Computação & NATA & $\mathrm{F}$ & 21 & Nutrição \\
\hline LID & $\mathrm{F}$ & 23 & Computação & ELIZ & $\mathrm{F}$ & 24 & Artes Plásticas \\
\hline
\end{tabular}



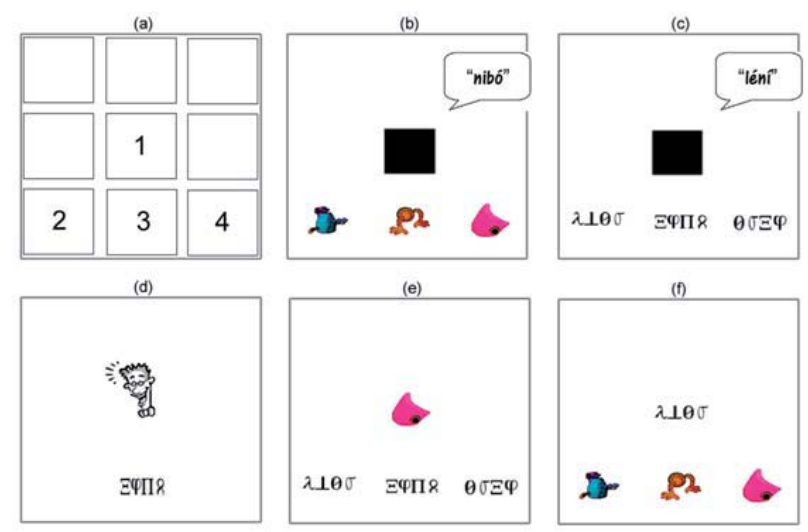

Figura 1. Configuração da tela do monitor em exemplos de diferentes situações: (a) localização das quatro janelas ativas; (b) Tentativa AB; (c) Tentativa AC; (d) Tentativa de Nomeação; (e) Tentativa BC; (f) Tentativa CB.

Os desenhos ambíguos (B) sugeriam semelhanças com animais e brinquedos e foram selecionados da biblioteca de estímulos do programa MTS. Cada estímulo $B$ tinha um único estímulo $C$ e um único estímulo $A$ correspondente. A Tabela 2 mostra quatro exemplares de estímulos definidos como correspondentes.

As relações entre estímulos são designadas por um par de letras, cada uma indicando o conjunto a que pertence o estímulo. Portanto, em tarefas de seleção, AB significa palavra ditada como modelo e figuras como estímulos de comparação; AC indica que o modelo era uma palavra ditada e as comparações eram palavras impressas (em alfabeto inventado); $\mathrm{BC}$ indica que o estímulo modelo era uma figura e os estímulos de comparação eram palavras impressas; e CB representa o inverso: uma palavra impressa era apresentada como modelo e os estímulos de comparação eram figuras. Para as relações estímulo-resposta, a primeira letra designa o conjunto a que pertence o estímulo e a segunda designa a modalidade de resposta; portanto, a nomeação oral das palavras impressas (comportamento textual, Skinner, 1957) é representada por $\mathrm{CD}$ : C indica uma palavra impressa e D indica a resposta vocal oral.

Tabela 2. Exemplos de Palavras faladas (A), impressas com o pseudo-alfabeto (C) e desenhos ambíguos (B) utilizados nas sessões de treino e/ou teste.

\begin{tabular}{cccc}
\hline $\begin{array}{c}\text { Grafia na } \\
\text { língua portuguesa }\end{array}$ & $\begin{array}{c}\text { Palavra ditada } \\
(\mathrm{A})\end{array}$ & $\begin{array}{c}\text { Palavra escrita } \\
(\mathrm{C})\end{array}$ & $\begin{array}{c}\text { Desenhos ambiguos } \\
\text { (B) }\end{array}$ \\
\hline NIBO & {$[$ nibó] } & $\Xi \varphi \Pi 8$ & \\
FALE & {$[$ fálé] } & $\lambda \perp \theta \sigma$ & \\
BOFA & {$[$ bófa] } & $\Pi 8 \lambda \perp$ & \\
LENI & {$[$ léni] } & $0 \sigma \Xi \varphi$ & \\
\hline
\end{tabular}

${ }^{1} \mathrm{O}$ acento agudo indica vogais com pronúncia aberta e sem nasalizaçăo. Todas as palavras foram pronunciadas

\section{Procedimento}

\section{Delineamento Experimental}

Foram realizados seis Ciclos Treinos-Testes e, ao final dos ciclos, foi conduzido um teste final de Nomeação oral das 12 palavras ensinadas e de um conjunto de 14 palavras novas, formadas pela recombinação de elementos das palavras ensinadas. Cada ciclo ensinava um subconjunto de relações e um novo ciclo só era iniciado depois que o participante atingisse o critério de aprendizagem no ciclo precedente. A Tabela 3 apresenta as palavras ensinadas e testadas em cada um dos seis ciclos e no teste final. Em cada ciclo, a seqüência de ensino e de testes seguiu a ordem indicada nas colunas 2 a 6. As palavras ensinadas em AC são as grafadas em caixa alta; as demais, em caixa baixa, são formadas por recombinações de elementos das primeiras e foram empregadas para avaliar generalização recombinativa.

Em cada ciclo, ensinavam-se relações $\mathrm{AB}$ e $\mathrm{AC}$ e testava-se a emergência de relações $\mathrm{BC}$ e $\mathrm{CB}$ e a emergência de leitura recombinativa. Relações $\mathrm{AB}, \mathrm{AC}, \mathrm{BC}$ e $\mathrm{CB}$ eram conduzidas com o procedimento de pareamento ao modelo (tarefas de seleção a serem descritas oportunamente, no detalhamento do procedimento). Os testes de leitura recombinativa eram realizados em tarefas de seleção e, também, em tarefas de nomeação (ver procedimento e Tabela 3 ).

$\mathrm{O}$ treino $\mathrm{AB}$ era realizado, em cada ciclo, com quatro pseudo-palavras (A) e quatro desenhos (B). Duas das relações desenho-palavra ditada eram diferentes em cada ciclo e duas eram repetidas em todos os ciclos (ver Tabela 3 ). As pseudopalavras das duas relações repetidas eram ensinadas apenas no Treino $\mathrm{AB}$ e eram importantes para possibilitar testes de leitura recombinativa com compreensão, que requeriam a utilização de palavras não ensinadas no Treino $\mathrm{AC}$, mas que já funcionavam como nome de algo (ou seja, possuíam um significado). O treino AC ensinava as relações entre duas das mesmas palavras faladas (A) e as correspondentes palavras escritas (C) com o pseudo-alfabeto. Os testes BC e CB são os testes típicos para avaliação da formação de classes de estímulos com base em uma linha de base $\mathrm{AB} / \mathrm{AC}$; portanto, avaliavam também a emergência de leitura com compreensão (Sidman, 1971,1994) das duas palavras ensinadas em AC e a emergência de leitura recombinativa com compreensão das duas palavras ensinadas no Treino $\mathrm{AB}$, mas não no Treino $\mathrm{AC}$.

Outras duas modalidades de leitura recombinativa eram avaliadas em seguida: a leitura recombinativa oral (Teste de Nomeação Oral ou CD) e a leitura recombinativa_receptiva (Teste AC). No Teste de Nomeação Oral, cada palavra era apresentada na tela e o participante era instruído a dizer a palavra. O Teste AC empregava a mesma tarefa que era utilizada no treino, mas que no teste era empregada para a avaliação de novas palavras formadas pela recombinação de letras das palavras ensinadas. Duas das quatro palavras utilizadas nesses testes eram aquelas ensinadas apenas no Treino $\mathrm{AB}$ e duas eram completamente novas. Cada novo ciclo repetia as mesmas tarefas, mas utilizava estímulos diferentes dos apresentados nos ciclos anteriores (exceto pelas duas palavras e respectivas figuras repetidas em todos os treinos $\mathrm{AB}$ e nos testes de recombinação). Ao final do sexto ciclo, 12 palavras diferentes haviam sido ensinadas, duas em cada ciclo (Ver Tabela 3). Os testes repetidos de leitura recombinativa a cada ciclo permitiam monitorar o desenvolvimento do controle pelas unidades textuais menores que a palavra e a emergência de leitura com compreensão. Após o sexto ciclo, realizava-se um Teste Final de Nomeação Oral com as 12 palavras ensinadas e as 14 palavras de recombinação (também listadas na Tabela 3). 
Tabela 3. Seqüência de ensino e de testes: palavras ensinadas (em caixa alta) e testadas (em caixa baixa) em cada um dos seis ciclos e no teste final. Em cada ciclo, a sequiência de ensino e de testes seguiu a ordem indicada nas colunas 2 a 6 .

\begin{tabular}{|c|c|c|c|c|c|}
\hline \multirow[t]{4}{*}{ Etapas } & \multicolumn{2}{|c|}{ Palavras ensinadas } & \multicolumn{3}{|c|}{ Palavras avaliadas } \\
\hline & & T. & Leitura com compreensão & Nomeação oral & Leitura receptiva \\
\hline & 1. Treino & 2. Treino & 3. Teste & 4. Teste CD & 5. Teste \\
\hline & & & $\mathrm{BC} / \mathrm{CB}$ & (parcial) & $\mathrm{AC}$ \\
\hline \multirow[t]{4}{*}{ Ciclo 1} & NIBO & NIBO & NIBO & nibe & nibe \\
\hline & FALE & BOLE & FALE & lofi & lofi \\
\hline & falo & - & falo & falo & falo \\
\hline & bena & - & bena & bena & bena \\
\hline \multirow[t]{4}{*}{ Ciclo 2} & BOFA & BOFA & BOFA & bofi & bofi \\
\hline & LENI & LENI & LENI & nale & nale \\
\hline & falo & - & falo & falo & falo \\
\hline & bena & - & bena & bena & bena \\
\hline \multirow[t]{4}{*}{ Ciclo 3} & LEBO & LEBO & LEBO & leba & leba \\
\hline & FANI & FANI & FANI & nofa & nofa \\
\hline & falo & - & falo & falo & falo \\
\hline & bena & - & bena & bena & bena \\
\hline \multirow[t]{4}{*}{ Ciclo 4} & BONI & BONI & BONI & bona & bona \\
\hline & LEFA & LEFA & LEFA & lefi & lefi \\
\hline & falo & - & falo & falo & falo \\
\hline & bena & - & bena & bena & bena \\
\hline \multirow[t]{4}{*}{ Ciclo 5} & FABO & FABO & FABO & fabe & fabe \\
\hline & NILE & NILE & NILE & nilo & nilo \\
\hline & falo & - & falo & falo & falo \\
\hline & bena & - & bena & bena & bena \\
\hline \multirow[t]{4}{*}{ Ciclo 6} & BOLE & BOLE & BOLE & febi & febi \\
\hline & NIFA & NIFA & NIFA & lano & lano \\
\hline & falo & - & falo & falo & falo \\
\hline & bena & - & bena & bena & bena \\
\hline Teste Final & \multirow{2}{*}{\multicolumn{5}{|c|}{$\begin{array}{l}\text { NIBO. FALE, BOFA, LENI, LEBO, FANI, BONI, LEFA, FABO, NILE, BOLE, NIFA } \\
\text { falo, bena, nibo, lofi, bofi, nale, leba, nofa, bona, lefi, fabe, nilo, febi, lano }\end{array}$}} \\
\hline $\begin{array}{l}\text { Nomeação Oral } \\
\text { (CD) }\end{array}$ & & & & & \\
\hline
\end{tabular}

\section{Descrição das Tarefas}

Os procedimentos de ensino e os testes eram conduzidos com tarefas de seleção e nomeação oral (ou comportamento textual) organizadas em uma seqüência de tentativas. Nas tentativas de seleção (Figura 1, painéis $b, c, e$ e $f$ ), os participantes selecionavam um estímulo de comparação, dentre os três apresentados nas janelas inferiores da tela. A tentativa era iniciada com a apresentação do estímulo-modelo ditado (nos emparelhamentos $\mathrm{AB}$ ou $\mathrm{AC}$ ) ou disposto na janela central (nos emparelhamentos BC e CB). Quando o modelo era ditado, um quadrado preto era simultaneamente apresentado na janela central (ver Figura 1, painéis $b$ e $c$ ). Uma resposta (pressão do botão esquerdo do mouse) sobre a área da janela central produzia os estímulos de escolha nas janelas inferiores. Apenas um estímulo de comparação era correto em cada tentativa. A posição do estímulo correto na tela era sistematicamente variada e uma resposta correta não incidia na mesma posição em mais do que duas tentativas consecutivas. Nos treinos, o número de estímulos de esco- lha foi aumentado gradualmente ao longo das tentativas. A primeira tentativa continha apenas o estímulo correto. Duas e depois três comparações incorretas foram utilizadas em etapas subseqüentes do treino. A passagem de uma etapa para outra estava condicionada a no máximo um erro nas tentativas daquela etapa. Se ocorressem mais erros em uma etapa, retornava-se para as tentativas da etapa anterior. Nos testes, o número de estímulos de escolha era três em todas as tentativas de seleção.

Nas tentativas de nomeação (Figura 1, painel $d$ ), um rosto sorridente era apresentado no centro da tela. O participante era instruído a pressionar sobre o desenho; sua resposta removia o rosto e iniciava a apresentação de uma palavra escrita com o pseudo-alfabeto na janela inferior central. $\mathrm{O}$ experimentador perguntava, então, que palavra era aquela. Nos treinos, respostas corretas em tentativas de seleção ou de nomeação eram seguidas por estrelas coloridas apresentadas na tela, juntamente com uma seqüência crescente de tons. Em caso de erro, a tentativa era encerrada e a tela permanecia escura por $3 \mathrm{~s}$. Nos testes, nenhuma consequiência foi progra- 
mada para respostas corretas ou incorretas. Ao final de cada tentativa, tinha início um intervalo de $1,5 \mathrm{~s}$ (intervalo entre tentativas), que terminava com a apresentação da tentativa seguinte. As sessões experimentais eram realizadas individualmente, três vezes por semana. A coleta de dados de um participante requeria, em geral, seis sessões.

\section{Etapas do procedimento}

Pré-treino. Antes do início do estudo, os participantes recebiam um treinamento na tarefa de seleção, no qual eram empregados estímulos utilizados apenas nessa etapa; cada estímulo era composto por uma figura geométrica (um quadrado ou um triângulo) colorida de vermelho ou preenchidas com padrões diferentes. Uma figura geométrica preenchida com um padrão era apresentada como modelo e as duas figuras coloridas eram apresentadas como estímulos de comparação. A resposta correta consistia em selecionar o estímulo de comparação com a mesma forma da figura-modelo.

Treino $A B$. No treino para estabelecer as relações entre palavra falada e figura, o computador ditava uma palavra, enquanto a tela mostrava um quadrado preto na janela central. Pressionar o botão do mouse com o cursor sobre o quadrado escuro produzia a oportunidade de escolher uma das figuras apresentadas nas janelas inferiores (ver Figura 1, quadro $b$ ).

Em cada ciclo treinavam-se quatro relações palavra-figura: duas com palavras utilizadas apenas no treino e duas com palavras de teste (ver Tabela 3). O número de estímulos de comparação foi gradualmente aumentado, conforme descrição das tarefas. O treino era encerrado quando o participante obtinha $100 \%$ de acertos no bloco final de 12 tentativas com três estímulos de comparação. O número mínimo de tentativas nesse treino, se o participante atingisse o critério de aprendizagem em todos os blocos de treino, era 60.

Treino AC. No treino para estabelecer as relações entre palavra falada e palavra impressa com o pseudo-alfabeto, o computador ditava uma palavra, enquanto a tela mostrava um quadrado preto na janela central. Pressionar o botão do mouse com o cursor sobre o quadrado escuro produzia a oportunidade de escolher uma das palavras escritas com o pseudo-alfabeto apresentadas nas janelas inferiores (ver Figura 1, Quadro $c$ ). A palavra impressa correta tinha três letras diferentes das letras das palavras incorretas apresentadas simultaneamente como estímulos de comparação. Em cada ciclo, eram ensinadas duas relações palavra falada-palavra impressa. Tentativas de nomeação das palavras impressas (CD) eram inseridas entre as tentativas AC. Nessas tentativas, uma palavra era apresentada sozinha e centralizada na parte inferior da tela (ver Figura 1, quadro $d$ ). O treino era finalizado quando ocorria $100 \%$ de acertos em um bloco de 12 tentativas, sendo seis do tipo AC e seis do tipo CD. Nesse treino, o número mínimo de tentativas, se o participante atingisse o critério de aprendizagem em todos os blocos, era 48.

Teste $B C / C B$. Concluídos os treinos das relações palavra ditada-figura e palavra ditada-palavra escrita, avaliava-se, então, a emergência das relações figura-palavra escrita BC (ver Figura 1, quadro $e$ ) e palavra escrita-figura CB (ver Figura 1 , quadro $f$ ) com os estímulos que haviam sido empregados nos dois treinos. Tentativas $\mathrm{BC}$ e $\mathrm{CB}$ eram intercaladas ao longo de um bloco de 12 tentativas, seis BC e seis CB.
Testes de Recombinação. Após os treinos eram realizados três tipos de testes de leitura recombinativa, empregando apenas palavras formadas pela recombinação de elementos das palavras ensinadas no Treino AC do ciclo.

A leitura recombinativa com compreensão era avaliada em quatro tentativas inseridas no Teste $\mathrm{BC} / \mathrm{CB}$, com os dois estímulos de teste utilizados no Treino $\mathrm{AB}$, mas não empregado no Treino AC (uma tentativa para cada palavra, duas BC e duas CB). Essas tentativas avaliavam se o participante selecionava, entre três figuras, aquela correspondente à palavra escrita (Figura 1, Quadro $f$ ) e, nas outras duas tentativas, se ele selecionava, entre as palavras escritas, aquela correspondente à figura apresentada na janela central (Figura 1, Quadro $e$ ). Acertos nessas tentativas podiam ser tomados como evidência de desenvolvimento do controle pelas unidades textuais menores que a palavra, uma vez que a sequiência de letras recombinadas em cada uma das duas palavras impressas, apresentadas pela primeira vez durante o teste, não havia sido apresentada no treino AC.

A leitura recombinativa oral era avaliada no Teste de Nomeação Parcial, em um bloco de oito tentativas de nomeação, no qual cada palavra era apresentada duas vezes em ordem semi-aleatória. Duas palavras eram novas e duas correspondiam às palavras ditadas no treino $\mathrm{AB}$ e relacionadas, portanto, apenas às figuras (ver Tabela 3 ). Em seguida, era avaliada a leitura recombinativa receptiva no Teste $\mathrm{AC}$, com as mesmas quatro palavras, em um bloco de oito tentativas (cada palavra era ditada duas vezes em ordem semi-aleatória). Essas tentativas avaliavam se o participante escolhia uma palavra escrita nova que correspondia à palavra ditada. A posição da palavra correta se repetia em, no máximo, duas tentativas consecutivas.

Após a conclusão dos seis ciclos, realizava-se um teste de nomeação com as 12 palavras ensinadas e as 14 palavras de recombinação (Teste de Nomeação Oral Final), em um bloco com 26 tentativas (cada palavra era apresentada uma vez). Todos os testes eram realizados em extinção, ou seja, cada resposta era seguida pela próxima tentativa, após o intervalo entre tentativas de $1,5 \mathrm{~s}$ com a tela escura. Cada teste era conduzido uma única vez, sem critério de desempenho (que era apenas medido) para prosseguir para a etapa seguinte.

\section{Resultados}

Todos os participantes aprenderam as relações ensinadas com poucos erros (especialmente no Treino $\mathrm{AB}$ ) e em uma sessão apenas. Ao longo dos ciclos, ocorreu redução no número de tentativas necessário para atingir o critério de aprendizagem nos Treinos AB e AC, exceto no segundo ciclo do Treino AC, em que se observou um aumento no número de tentativas quando comparado com o primeiro ciclo. No último ciclo, o número mínimo de tentativas programado para cada treino (60 no Treino AB e 48 no AC) foi, em geral, suficiente para a aquisição de todas as relações ( $100 \%$ de acertos no bloco final do treino). Os resultados foram semelhantes para os alunos de ciências exatas e humanas. Embora nos primeiros três ciclos do Treino AC o número de tentativas para atingir o critério de aprendizagem tenha sido ligeiramente menor para alunos de exatas que os de humanas, testes estatísticos não revelaram diferenças significativas entre as médias dos dois grupos ( $p>0,05$, exceto no Ciclo 4 do Treino AC). 
Os escores no Teste BC/CB com os estímulos incluídos nos treinos $\mathrm{AB}$ e $\mathrm{AC}$ foram altos (em geral 100\% de acertos) em todos os ciclos, o que evidencia que ocorreu a emergência das relações entre palavras escritas com o pseudo-alfabeto e figuras (leitura com compreensão), a partir dos treinos. Escores semelhantes foram observados para alunos de ciências exatas e humanas.

Os resultados dos testes de leitura recombinativa de cada ciclo, para alunos de ciências exatas (símbolos cheios) e humanas (símbolos vazios), são apresentados na Figura 2, médias de grupo. As percentagens de acerto de leitura recombinativa com compreensão (Teste $\mathrm{BC} / \mathrm{CB}$, painel da esquerda), de leitura recombinativa receptiva (Teste AC, painel central) e de leitura recombinativa oral (Teste de Nomeação Parcial, painel da direita) são apresentadas lado a lado para fins de comparação. Nas três modalidades de teste de recombinação, com palavras formadas pela recombinação das letras das palavras de treino, o percentual de acertos aumentou ao longo dos ciclos, em função do número de palavras ensinadas, para os participantes dos dois grupos. Os escores nos testes $\mathrm{BC} / \mathrm{CB}$ e $\mathrm{AC}$ (gráficos à esquerda e central), que programavam tentativas de seleção com três estímulos de comparação (e 33,3\% de probabilidade de acertos ao acaso), foram bastante semelhantes: as percentagens de acerto ficaram ao redor de $50 \%$ após o ensino de duas palavras para os dois grupos e aumentaram gradualmente com o aumento de palavras ensinadas. $\mathrm{O}$ aumento apresentado pelos participantes de humanas foi, em média, menor do que o apresentado pelos participantes de exatas (diferença estatisticamente significativa $-p=0,02)$. Nos Testes de Nomeação Parciais (Figura 2, gráfico à direita), os escores após os dois ciclos iniciais foram bem mais baixos (próximos de zero) do que nos testes com tentativas de seleção, mas também aumentaram linearmente com o número de palavras ensinadas ao longo dos ciclos. No início do estudo, estudantes de ciências exatas e humanas apresentaram escores baixos e próximos, em geral, abaixo de $25 \%$ de acerto no primeiro ciclo (com duas palavras ensinadas). Após a aquisição das relações AB e AC com seis palavras diferentes (Ciclo 3) mas compostas pelas mesmas sílabas, ocorreu um aumento substancial da leitura recombinativa para alunos dos cursos de exatas, mas não para os alunos de cursos de humanas (diferença estatisticamente significativa $-p=0,02$ ). Em média, os alunos de exatas apresentaram maior grau de leitura recombinativa do que os de cursos da área de humanidades ao longo dos ciclos, mas essas diferenças não foram significativas (exceto no Ciclo 3). Os desempenhos médios de ambos os grupos apresentaram tendência crescente até o último ciclo, quando

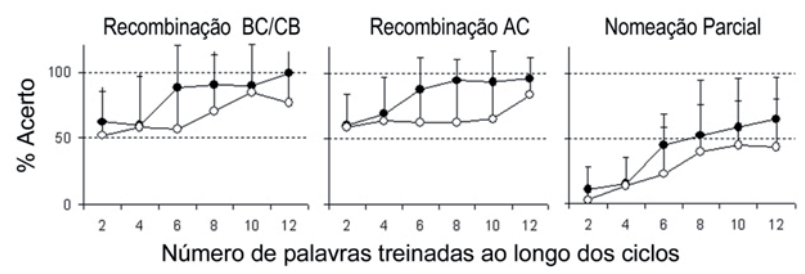

Figura 2. Percentagem de acerto (média) nos Testes de Recombinação: BC/CB (gráfico à esquerda); $\mathrm{AC}$ (gráfico central); e de Nomeação (gráfico à direita) para participantes dos cursos das áreas de exatas (símbolos cheios) e humanas (símbolos vazios). As barras verticais representam um desvio padrão da média. se aproximaram de $100 \%$ nos testes $\mathrm{BC} / \mathrm{CB}$ e $\mathrm{AC}$ e de $50 \%$ (humanas) a $75 \%$ (exatas) na nomeação de palavras.

A Figura 3 apresenta a distribuição de freqüência de participantes que apresentaram a primeira nomeação correta em palavra de recombinação em cada ciclo, para participantes da área de exatas (círculos cheios) e da área de humanidades (círculos vazios). Observa-se que metade dos estudantes do grupo exatas (5) apresentou recombinação já no primeiro ciclo, quando apenas duas palavras haviam sido ensinadas. Após o ensino de seis palavras (Ciclo 3), todos os estudantes de exatas haviam apresentado uma primeira recombinação. Por outro lado, os alunos de humanas se distribuíram ao longo dos diversos ciclos e apenas seis dos 10 participantes apresentaram leitura recombinativa após o ensino de seis palavras (Ciclo 3). Entretanto, esses resultados mostram que, apesar das diferenças na distribuição de freqüência da primeira recombinação, todos os participantes dos dois grupos leram corretamente pelo menos uma palavra com recombinação de letras até o Ciclo 5, com o ensino de 10 palavras.

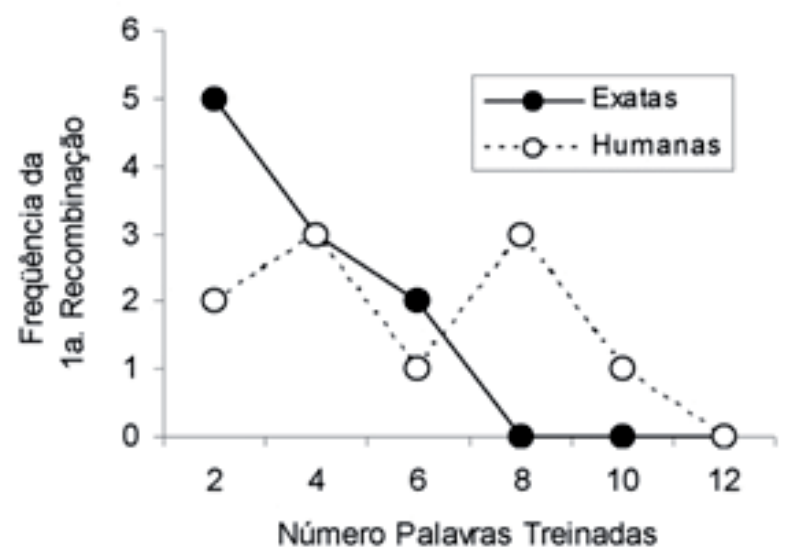

Figura 3. Distribuição de freqüência de participantes dos cursos das áreas de exatas (símbolos cheios) e humanas (símbolos vazios) que apresentaram a primeira recombinação (nomeação correta da primeira palavra com recombinação) com os diferentes números de palavras treinadas.

A medida final de leitura recombinativa foi obtida no Teste de Nomeação Final que incluiu todas as palavras ensinadas (12 dissílabos compostos por combinações de quatro sílabas diferentes) e os 14 dissílabos formados por recombinações das oito letras. A Figura 4 mostra o desempenho individual de participantes da área de exatas (gráficos à esquerda), humanas (gráficos no centro) e as médias para cada grupo (gráficos à direita). Os gráficos na parte superior da figura mostram os resultados da leitura de palavras empregadas nos treinos e os gráficos na parte inferior da figura apresentam os resultados de leitura recombinativa (generalização para palavras novas). Aspectos da pronúncia na leitura, como nasalização de vogal - FÃNI em vez de FÁNI; vogal fechada - BÔLÉ em vez de BÓLÉ; tônica na primeira sílaba - BÓLE em vez de BÓĹ́, foram desconsiderados nesta análise. Nove dos 10 universitários do grupo exatas (gráficos à esquerda) apresentaram escores acima de $75 \%$ em palavras ensinadas e recombinadas, enquanto que no grupo humanas (gráficos no centro), apenas quatro dos 10 participantes obtiveram escores semelhantes para palavras ensinadas e recombinadas. 
EXATAS

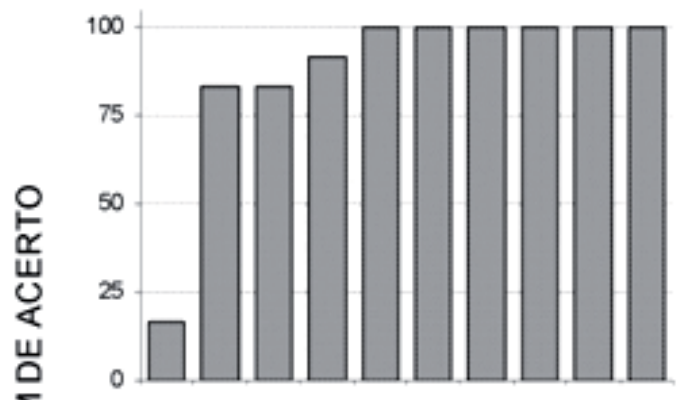

PALAVRAS DE TREINO

HUMANAS

Grupo - Pal. Treino
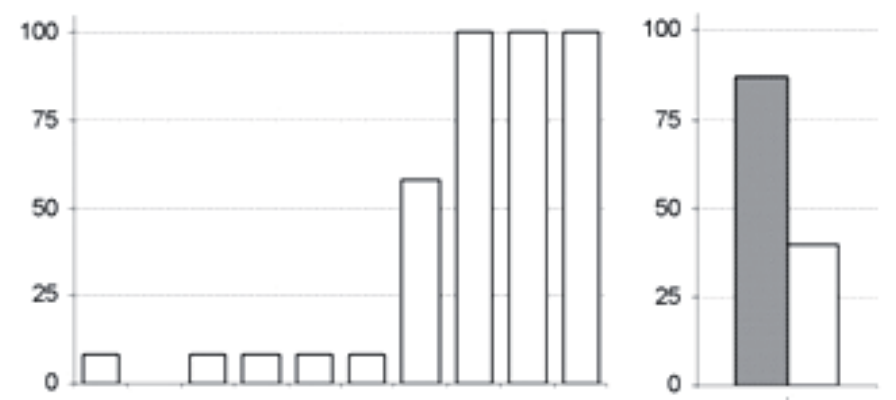

PALAVRAS COM RECOMBINAÇÃO

Grupo - Pal. Recomb.

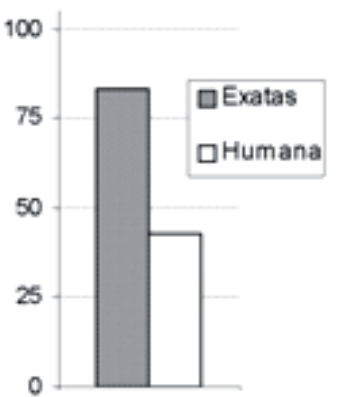

PARTCIPANTES

Figura 4. Percentagem de acerto individual e do grupo (média) para palavras de treino (gráficos superiores) e de recombinação (gráficos inferiores) no Teste de Nomeação Final, realizado após o treino das 12 palavras, para os participantes das Áreas de Ciências Exatas e Humanas.

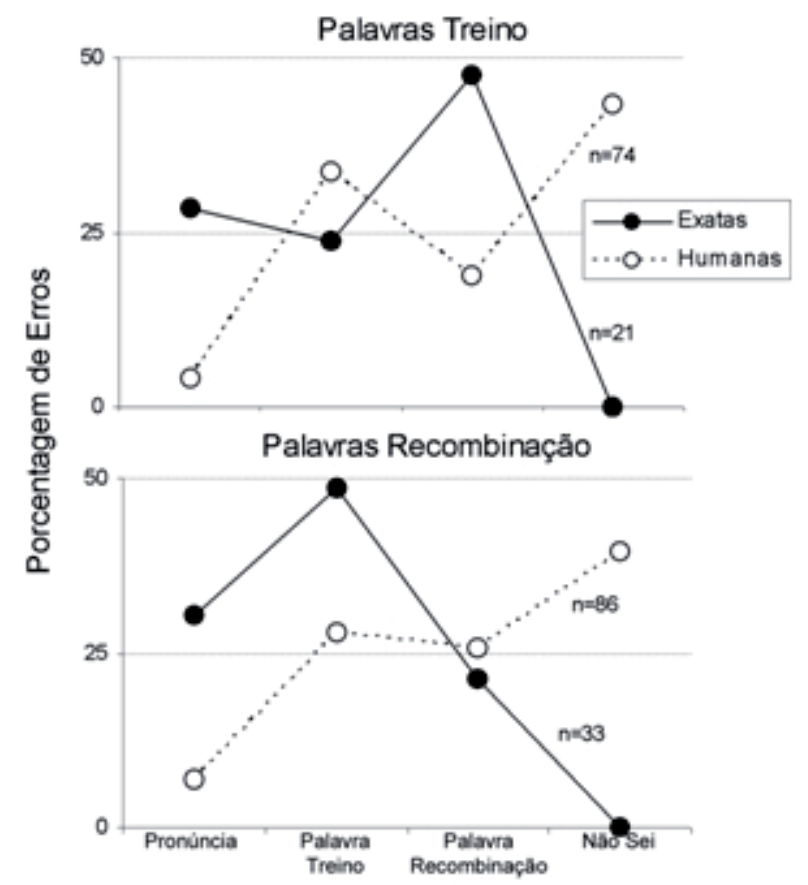

Tipos de Erro

Figura 5. Freqüência relativa de quatro categorias de erros na nomeação de palavras de treino (gráfico superior) e de recombinação (gráfico inferior) apresentados pelos participantes dos cursos das áreas de exatas (símbolos cheios) e humanas (símbolos vazios).
Os escores individuais refletem um efeito tudo ou nada, ou seja, os alunos que apresentaram leitura obtiveram escores elevados; os outros mostraram nenhuma leitura ou leitura incipiente. Quando se consideram as médias de grupo, alunos de exatas apresentaram escores significativamente maiores (aproximadamente o dobro) em leitura oral do que alunos de humanas, tanto para palavras ensinadas, como para palavras recombinadas $(p=0,01$ para palavras de treino e recombinação). Observa-se, portanto, que para cada grupo, os escores na leitura com palavras de treino foram semelhantes aos escores na leitura de palavras de recombinação, isto é, os alunos que apresentaram leitura oral, leram tanto palavras ensinadas quanto palavras novas; os alunos que não leram palavras novas, também não leram corretamente as palavras ensinadas no Treino AC. Para sete participantes (um do grupo de exatas e seis do grupo de humanas), os escores de nomeação das palavras testadas em conjunto foram menores do que $25 \%$, embora no teste de nomeação parcial, realizado ao final dos treinos de cada ciclo, esses participantes tivessem acertado $100 \%$ das tentativas de nomeação que continham as duas palavras ensinadas em cada ciclo.

Os erros cometidos no Teste Final de Recombinação foram analisados a partir de quatro categorias de resposta: erro de pronúncia, uso de uma palavra do treino em lugar da palavra recombinada, uso de uma palavra com recombinação de letras mas que não correspondia à palavra testada e recusa

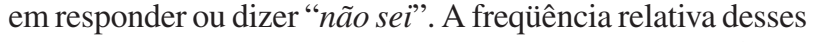
erros (porcentagem) para cada grupo é apresentada na Figura 5 , separadamente para as palavras de treino (painel superior) 
e recombinadas (painel inferior). A distribuição de erros foi diferente para os estudantes de cursos de exatas e de humanas. O grupo humanas cometeu poucos erros de pronúncia, mas não tentava ler a palavra ou dizia "não sei" com freqüência. Nas ocorrências de erro, diziam uma palavra de treino ou uma com recombinação. $\mathrm{O}$ grupo exatas sempre tentava ler as palavras (a categoria "não sei" não ocorreu - isto é, teve porcentagem zero) mesmo cometendo vários erros de pronúncia (aproximadamente 25\% do total de erros do grupo). Para esse grupo, os erros mais freqüientes consistiram em dizer uma palavra com recombinação quando a palavra impressa era uma de treino e dizer uma palavra de treino quando a palavra impressa era de recombinação (em geral, as respostas consistiam de aproximações da palavra correta).

Nesses resultados, todas as respostas seguiram a estrutura das palavras utilizadas no estudo (dissílabo, composto pelas letras A, B, E, F, I, L, N, O, em seqüência Consoante-Vogal-Consoante-Vogal). Esta análise, apesar de bastante informativa, deve ser considerada com cautela devido à discrepância no número de erros e variabilidade individual nos dois grupos. No grupo exatas, vários participantes não cometeram erros (seis participantes em palavras de treino e quatro em palavras com recombinação) e apenas um cometeu muitos erros; portanto a distribuição dos erros desse grupo reflete muito mais o desempenho de MAN e é pouco representativa da amostra.

\section{Discussão}

O presente estudo investigou o efeito da quantidade de pseudo-palavras ensinadas, compostas pelas mesmas sílabas, sobre o desenvolvimento de leitura recombinativa. O estudo foi realizado com estudantes universitários das áreas de exatas e de humanas, utilizando um Sistema Lingüístico em Miniatura com um alfabeto inventado, composto por oito letras com correspondência unívoca com oito fonemas. Uma versão simplificada de procedimentos de ensino de leitura, utilizados em estudos anteriores (e.g., de Rose \& cols., 1996), foi desenvolvida e o programa foi aplicado via computador.

Análises separadas para participantes de cursos da área de ciências exatas e humanas mostraram desempenhos semelhantes nos treinos, mas não em testes de leitura recombinativa.

A quantidade de treino necessária para aprender as relações entre as palavras ditadas, seus referentes (figuras) e símbolos escritos com o alfabeto inventado foi semelhante. Todos os participantes obtiveram $100 \%$ de acertos nos diferentes treinos, atingindo esse critério de aprendizagem em uma única sessão para cada ciclo de treino.

O número de tentativas necessário para a aprendizagem das relações condicionais entre as palavras faladas e impressas (AC) diminuiu do segundo para o sexto ciclo, sugerindo um efeito da história de aprendizagem de discriminações sobre a aprendizagem de novas discriminações. Esse fenômeno, chamado de learning set (Catania, 1992; Harlow, 1949), é comum em estudos que programam treinos discriminativos semelhantes com múltiplos exemplares. Os treinos de discriminações condicionais por emparelhamento com o modelo em todos os ciclos, modificando-se apenas o conjunto de estímulos utilizados, possibilitou a transferência de habilidades aprendidas em um ciclo para ciclos subseqüentes que programavam contingências de reforçamento semelhantes. Nos últimos ciclos, a maioria dos participantes aprendeu as relações condicionais com o número mínimo de tentativas programadas. A ocorrência de learning set com um sistema lingüístico em miniatura sugere que a redução dos estímulos utilizados pode ser uma estratégia eficaz de ensino de redes de discriminações complexas, como as requeridas na leitura. A redução do número de estímulos (letras e sílabas, no presente estudo) aumenta a densidade de reforçamento de respostas na presença de cada estímulo em diferentes posições, quando comparado com procedimentos que utilizam todas as 23 letras do alfabeto português (Oliveira-Castro, 2000). A redução do número de elementos, aliada ao uso de treinos semelhantes, pode ter sido responsável pela rápida aquisição das discriminações relevantes para a aprendizagem de leitura. O presente estudo foi replicado com crianças pré-escolares, utilizando-se apenas oito letras do alfabeto português (de Jesus, 2005). As sete participantes mostraram resultados semelhantes aos relatados neste estudo.

Os escores de leitura de palavras ensinadas no teste final foram semelhantes aos obtidos para palavras de recombinação, isto é, todos os participantes que leram as palavras que haviam sido incluídas nos treinos (em tarefas de seleção) também leram palavras novas formadas pela recombinação de elementos das palavras ensinadas. Por outro lado, um participante do grupo exatas e seis do grupo humanas erraram todas ou quase todas as nomeações no teste final, quer a palavra tivesse sido ensinada ou fosse uma palavra recombinada. À primeira vista esse resultado pode provocar estranheza, considerando que todos os participantes atingiram $100 \%$ nos treinos AC, que incluíam tentativas de nomeação das palavras e a exigência de acerto para sua finalização. Por que, então, uma retenção tão baixa desses participantes no teste final? Os escores desses participantes em leitura recombinativa sugerem que a discriminação desenvolvida durante os treinos pode ter sido baseada na configuração geral das palavras (palavra como ícone) ou em aspectos irrelevantes que diferenciavam as palavras (primeira ou última sílaba, por exemplo). A discriminação entre palavras baseada em sua configuração geral ou em aspectos específicos no SLM planejado era uma aprendizagem útil e suficiente dentro do contexto de cada ciclo que envolvia apenas duas palavras, por exemplo, NIBO e FALE. Os participantes rapidamente aprendiam que uma das duas palavras estaria presente em cada tentativa e ela seria a alternativa correta. As outras palavras apresentadas em cada tentativa tinham apenas uma letra em comum com a palavra correta e na mesma posição, o que possibilitava acertos com base em duas letras apenas. Essa aprendizagem foi suficiente para obter sucesso na situação de treino, mas não era funcional e poderia produzir confusão no teste, quando o contexto mudava para múltiplas palavras muito semelhantes e as respostas não tinham feedback. Nesse teste final, além de um número maior de palavras (26), existiam muitos aspectos comuns entre as palavras (por exemplo, NIBO, NIBE e NILO) que favoreciam a ocorrência de generalização (responder semelhante na presença de estímulos diferentes) quando letras individuais ainda não controlavam respostas específicas.

Além de aprenderem as relações ensinadas entre palavras ditadas e figuras e palavras ditadas e impressas, todos os participantes demonstraram a formação de classes de estímulos equivalentes pela emergência de relações entre as figuras 
(referente) e as palavras impressas (BC/CB), sugerindo o desenvolvimento de leitura com compreensão (Sidman, 1994). Esses resultados replicam, com estudantes universitários e um SLM inventado, aqueles obtidos com crianças em estudos sobre leitura com o alfabeto português (e.g., de Rose \& cols., 1996; de Souza, de Rose, Hanna, Calcagno \& Galvão, 2004; Matos \& cols., 1997, 1999, Matos \& cols., 2006; Melchiori \& cols., 2000). Nesse caso, também, pode-se perguntar por que os sete participantes que apresentaram baixos escores em leitura oral não apresentaram a mesma dificuldade nessas tarefas. É preciso considerar que essas eram tarefas de seleção, nas quais o participante não tinha que construir sua resposta, bastava selecionar um dos três estímulos de comparação. Com o estímulo modelo e os estímulos de comparação presentes, a configuração contém muitos elementos que podem fornecer pistas para a resposta correta, que pode ser baseada em algum aspecto do estímulo, mas não requer o controle de cada um dos elementos e de sua seqüência para a emissão da resposta, como é o caso na leitura oral. Esses resultados replicam os encontrados com crianças que estavam aprendendo a ler com o alfabeto português: os escores nas tarefas de seleção foram sistematicamente maiores que os escores em leitura oral, para alunos que apresentavam baixos escores na leitura oral (de Souza \& cols., 1997).

As diferenças de desempenhos de um mesmo indivíduo observadas nas três diferentes tarefas que avaliaram leitura recombinativa (Testes BC/CB, Teste AC e Teste de Nomeação Oral), que puderam ser identificadas para os sete participantes que não apresentaram leitura oral no teste final, apóiam a noção de que o repertório de leitura se caracteriza por uma rede de relações, que se encontram perfeitamente interligadas no repertório de um leitor proficiente, mas que podem ser adquiridas independentemente e em diferentes ritmos, ao longo de um programa de ensino (de Rose, 2005; de Rose \& cols., 1996; de Souza \& de Rose, 2006). Esses resultados permitem ressaltar a importância do emprego de medidas múltiplas, como as empregadas neste estudo, para uma caracterização precisa do repertório, tanto para fins de pesquisa científica, quanto para a monitoração do desempenho individual (e as necessárias correções ou intervenções) em situações de ensino, em que se tem como objetivo transformar o não-leitor em leitor competente.

Em geral, leitura recombinativa se desenvolveu gradualmente e os escores foram diretamente proporcionais ao aumento das palavras/relações ensinadas ao longo dos ciclos. O processo de aquisição se mostrou variável de indivíduo para indivíduo, cada um iniciando a recombinação após um número diferente de palavras ensinadas. Entre os estudantes de cursos de exatas, alguns começaram a apresentar a primeira recombinação logo após o ensino das duas primeiras palavras e todos eles estavam apresentando leitura de palavras recombinadas após o treino de seis palavras. Os estudantes de cursos de ciências humanas mostraram uma variabilidade maior na quantidade de treino que precedeu a ocorrência da primeira recombinação (Figura 3). O efeito da quantidade de treino e a variabilidade inter-sujeitos já foram relatados anteriormente na literatura. De Rose e cols. (1996) mostraram, com crianças com dificuldade de aprendizagem e com o alfabeto português, que esses desempenhos emergiram em graus diferentes ao longo do programa de ensino. Algumas crianças, entretanto, mesmo após o ensino de 51 palavras, não apresentaram leitura recombinativa. Outros estudos relataram resultados similares (e.g., de Rose, de Souza, Rossito \& de Rose, 1989; de Souza \& cols., 2004; Matos \& cols., 1999; Melchiori \& cols., 2000). Rocha (1996) observou, com um pseudo-alfabeto semelhante ao utilizado neste estudo, que independente da manipulação da estrutura das palavras de treino em condições experimentais diferentes, a recombinação foi maior na última condição, quando mais palavras haviam sido ensinadas. Exceto pela manipulação na composição dos estímulos textuais, o procedimento deste estudo programou conseqüências para desempenhos em relação a palavras inteiras, e não para desempenhos que requeressem uma recombinação ativa pelo participante. Nessa condição, o controle por unidades menores que a palavra inteira pode se desenvolver, como foi previsto por Skinner (1957), demonstrado em estudos prévios (e.g., de Rose \& cols., 1996; de Souza \& cols., 1999, 2004; Matos \& cols., 1997, 1999, Matos \& cols., 2006; Melchiori \& cols., 2000) e replicado neste estudo. Contudo, essa característica do procedimento deixa ampla margem para variabilidade comportamental, dada a complexidade dos estímulos textuais e o fato de que as consequiências programadas para respostas corretas podem atuar seletivamente sobre uma diversidade de relações de controle de estímulos não previstas pelo experimentador (Dube \& Mcllvane, 1996; Mcllvane, 1998; McIlvane \& Dube, 1992; Ray \& Sidman, 1970).

Todos os participantes do presente estudo leram alguma palavra com recombinação nos testes parciais. A diferença entre eles está no grau e na velocidade com que a recombinação ocorreu. Os estudantes de exatas foram mais rápidos e apresentaram escores mais elevados. Os estudantes de humanas precisaram de mais treino para apresentar recombinação consistente; os escores intermediários ou baixos da maioria dos participantes sugerem que a quantidade de treino programada neste estudo não foi suficiente para esses participantes. Neste estudo, foram esgotadas todas as possibilidades de recombinação das quatro sílabas em dissílabos de treino ao longo dos ciclos. Portanto, não seria possível aumentar a quantidade de palavras ensinadas se o mesmo critério para a construção das palavras fosse mantido. $\mathrm{O}$ critério utilizado foi interessante por manter constante a quantidade de treino na presença de cada letra e sílaba em todos os ciclos. É possível que um delineamento de linha de base cumulativa, em que palavras de ciclos anteriores fossem retreinadas junto com novas palavras, acelere o processo de recombinação, por adicionar ao procedimento um aumento na variedade dos estímulos em um mesmo contexto, que planeja conseqüências para respostas na presença de palavras diferentes. Portanto, sob as condições do presente estudo, os resultados permitem concluir que a leitura recombinativa, quando ocorreu, foi função direta da quantidade de palavras ensinadas. Se uma ampliação sistemática na quantidade de palavras ensinadas pode resultar em leitura recombinativa para todos os participantes de um estudo como este, é uma questão que requer a condução de estudos planejados especificamente para investigar essa possibilidade.

No que concerne à história pré-experimental dos participantes, a leitura recombinativa se desenvolveu, a partir do treino das relações entre palavras ditadas e as figuras e palavras impressas correspondentes envolvendo 12 palavras, 
para nove dos 10 participantes de cursos da área de exatas (exceto MAN). Entretanto, apenas quatro participantes da área de humanas apresentaram escores iguais a ou maiores que $75 \%$ de acerto no teste final (Figura 4), sendo essa diferença significativa. O padrão de responder dos dois grupos, refletido na frequiência relativa de categorias de erros (Figura 5), também foi diferente: estudantes de exatas sistematicamente tentavam ler as palavras do teste e, em geral, quando erravam, utilizavam em sua resposta uma aproximação da resposta correta; estudantes de humanas com frequiência diziam "não sei”. Não obstante, os dois grupos apresentaram desempenhos semelhantes na aquisição das relações ensinadas (AB e AC). Como interpretar as diferenças encontradas entre os grupos? Uma hipótese para explicar os resultados é que as diferentes áreas refletem diferenças na quantidade de treino de relações simbólicas e na motivação para a tarefa. Alunos de ciências exatas cursam um número maior de disciplinas que utilizam a linguagem matemática e outros símbolos, como a química, física e matemática, e conseqüentemente são mais treinados em diferentes modalidades de relações simbólicas. Esse treino extensivo de utilização de símbolos, por ser semelhante ao ensinado e avaliado neste estudo, pode ter facilitado a aquisição e a emergência das relações com novos estímulos. Além disso, a escolha por uma das áreas já pode refletir a motivação para as disciplinas mencionadas, o que, por sua vez, se refletirá no desempenho em tarefas que requeiram a aprendizagem de correspondência entre símbolos. Afirmações mais conclusivas sobre esses resultados só poderão ser feitas, entretanto, quando estudos adicionais sobre as diferenças na história e motivação desses estudantes forem realizados. A importância desses achados não deve ser obscurecida pela dificuldade de interpretação, entretanto, considerando-se que a utilização de universitários é uma prática comum em experimentos psicológicos em geral (Cozby, 2003; Sears, 1986; Smart, 1966) e sobre aprendizagem de relações arbitrárias em particular. Os resultados apresentados neste trabalho sugerem um maior cuidado na seleção da amostra e na prevenção de viés que a utilização de estudantes de apenas um curso pode produzir nos resultados.

No presente estudo, um sistema lingüístico em miniatura foi utilizado para avaliar o processo de aquisição de relações simbólicas presentes no repertório de leitura. O sistema foi composto por oito letras inventadas que formavam dissílabos na forma gráfica e oral. Cada símbolo gráfico era correspondente a um fonema da língua portuguesa, sendo quatro vogais (A, E, I e O) e quatro consoantes (B, F, L e N). As palavras eram pronunciadas como oxítonas e as vogais abertas. Foram utilizadas pseudo-palavras sem significado na língua portuguesa. Para parte das palavras foram designadas figuras correspondentes. O sistema lingüístico simplificado serviu de base para o ensino de relações entre palavras ditadas, palavras impressas e figuras (referentes). Sistemas lingüísticos em miniatura têm sido utilizados em outros contextos para analisar as relações funcionais entre variáveis ambientais e desenvolvimento de linguagem (e.g., Goldstein, 1981, 1983). A metodologia empregada no presente estudo possibilitou o estudo do desenvolvimento de controle por elementos textuais mesmo quando os participantes dominavam a leitura e escrita de outras línguas. As curvas de aprendizagem obtidas com os universitários mostraram que a leitura recombinativa se desenvolveu gradualmente, como ocorre na aprendizagem de leitura da primeira língua. Além disso, a variabilidade na velocidade de aquisição da leitura encontrada neste estudo com universitários replicou resultados anteriores com crianças pré-escolares (Rocha, 1996) ou que apresentavam dificuldade de aprendizagem (de Rose \& cols., 1996). Apesar das semelhanças encontradas nos resultados com crianças e adultos, as diferenças são também relevantes. Em estudos com crianças, a variabilidade individual encontrada se assemelha à mostrada pelos estudantes da área de humanas. Além disso, a aquisição das discriminações condicionais $\mathrm{AB}$ e $\mathrm{AC}$ e de leitura recombinativa foi mais rápida entre os universitários. Essas diferenças, quando comparadas às diferenças entre universitários de exatas e humanas, apóiam a explicação baseada no efeito de história com relações simbólicas sobre a velocidade de aquisição de discriminações ensinadas e do desenvolvimento de leitura recombinativa.

Com esse sistema lingüístico inventado foi possível controlar, pelo menos em parte, a história de reforçamento (treino discriminativo) com os estímulos utilizados e avaliar a aquisição de relações ensinadas e emergentes em estudantes universitários, simulando estágios iniciais de aquisição de leitura. A estratégia experimental de ciclos treinos-testes possibilitou monitorar a aprendizagem individual das relações ensinadas e a emergência de novas relações e, também, construir uma história de reforçamento em pouco tempo, mas com um efeito poderoso sobre a aquisição de linguagem (leitura). O uso de palavras como unidade textual nas sessões de ensino foi suficiente para gerar leitura recombinativa, principalmente em universitários de ciências exatas. Será importante avaliar outras condições de treino que podem afetar o grau e a variabilidade de leitura recombinativa observada com estudantes de ciências humanas. Como os desempenhos desses participantes se assemelharam aos obtidos com crianças e com situações de aprendizagem com o alfabeto português, resultados de novos estudos poderão favorecer uma melhor compreensão dos processos envolvidos na aprendizagem de leitura e fundamentar procedimentos e metodologias de ensino alternativas.

\section{Referências}

Adams, M. J. (1994). Beginning to read: Thinking and learning about print. Cambridge: MIT Press.

Albuquerque, A. R. (2001). Controle comportamental por símbolos compostos: manipulação da similaridade entre estímulos discriminativos e do número de recombinações treinadas. Tese de Doutorado, Universidade de Brasília, Brasília.

Alessi, G. (1987). Generative strategies and teaching generalization. The Analysis of Verbal Behavior, 5, 15-27.

Catania, A. C. (1992). Learning. Englewood Cliffs: Prentice-Hall.

Cozby, P. (2003). Métodos de pesquisa em ciências do comportamento. (P. I. C. Gomide \& E. Otta, Trad.). São Paulo: Atlas.

Cumming, W. W. \& Berryman, R. (1965). The complex discriminated operant: Studies of matching-to-sample and related problems. Em D. I. Mostofsky (Org.), Stimulus generalization (pp. 284-330). Standford: Standford University Press.

de Jesus, P. S. (2005). Aprendizagem de leitura e emergência de repertório recombinativo em crianças pré-escolares. Dissertação de Mestrado, Universidade de Brasília, Brasília. 
de Rose, J. C. (1993). Classes de estímulos: implicações para uma análise comportamental da cognição. Psicologia: Teoria e Pesquisa, 9, 283-303.

de Rose, J. C. (2005). Análise comportamental da aprendizagem de leitura e escrita. Revista Brasileira de Análise do Comportamento, l(1), 29-50.

de Rose, J. C., de Souza, D. G. \& Hanna, E. S. (1996). Teaching reading and spelling: Exclusion and stimulus equivalence. Journal of Applied Behavior Analysis, 29, 451-469.

de Rose, J. C., de Souza, D. G., Rossito, A. L. \& de Rose, T.M.S. (1989). Aquisição de leitura após história de fracasso escolar: equivalência de estímulos e generalização. Psicologia: Teoria e Pesquisa, 5(3), 325-346.

de Souza, D.G. \& de Rose, J.C. (2006). Desenvolvendo programas individualizados para o ensino de leitura. Acta Comportamentalia, 14(1), 77-98.

de Souza, D. G., de Rose, J. C., Hanna, E. S., Calcagno, S. \& Galvão, O. F. (2004). Análise comportamental da aprendizagem de leitura e escrita e a construção de um currículo suplementar. Em M. M. C. Hübner \& M. Marinotti (Orgs.), Análise do comportamento para a educação: Contribuições recentes (pp. 177-203). Santo André: ESETec Editores Associados.

de Souza, D.G., Hanna, E. S., de Rose, J. C., Fonseca, M.L., Pereira, A. B. \& Sallorenzo, L. H. (1997). Transferência de controle de estímulos de figura para texto no desenvolvimento de leitura generalizada. Temas em Psicologia, 1, 33-46.

de Souza, D. G., de Rose, J. C., Fonseca, M. L. \& Hanna, E. S. (1999). Stimulus control research and minimal units for reading. Experimental Analysis of Human Behavior Bulletin, 17, 20-23.

Dube, W. V. (1991). Computer software for stimulus control research with Macintosh computers. Experimental Analysis of Human Behavior Bulletin, 9, 28-30.

Dube, W. V. \& McIlvane, W. J. (1996). Some implications of a stimulus control topography analysis for emergent behavior and stimulus classes. Em T. R. Zental \& P. M. Smeets (Orgs.), Stimulus class formation in humans and animals (pp. 197-218). Amsterdam: North Holland/Elsevier.

Esper, E. A. (1925). A technique for the experimental investigation of associative interference in artificial linguistic material. Language Monography, 1, 1-45.

Esper, E. A. (1933). Studies in linguistic behavior organization: I. Characteristics of unstable verbal reactions. Journal of Genetic Psychology, 8, 346-379.

Foss, D. J. (1968). An analysis of learning in a miniature linguistic system. Journal of Experimental Psychology, 76, 450-459.

Goldstein, H. (1981). The effects of lexical learning histories on the generative language acquisition of preschool children. Dissertation Abstracts International, 42, 796-797.

Goldstein, H. (1983). Training generative repertoires within agentaction-object miniature linguistic systems with children. Journal of Speech and Hearing Research, 26(1), 76-89.

Hanna, E. S., de Albuquerque, A. R., Quinteiro, R. S. \& Kohlsdorf, M. (2004, maio). Sistema simbólico em miniatura e aprendizagem de leitura com crianças e adultos. Anais do X Simpósio de Pesquisa e Intercâmbio Científico da Associação Nacional de Pesquisa e Pós-Graduação em Psicologia (pp. 26-27). Vitória, ES.

Harlow, H. F. (1949). The formation of learning sets. Psychological Review, 56, 51-65.
Horowitz, A. E. \& Jackson, H. M. (1959). Morpheme order and syllable structure in the learning of miniature linguistic systems. Journal of Abnormal and Social Psychology, 59, 387-392.

Hübner, M. M. C., Matos, M. A. \& Serra, C. (2002). Redes de relações condicionais e leitura recombinativa: pesquisando o ensinar a ler. Arquivos Brasileiros de Psicologia, 52, 284-303.

Kennedy, A. E. (1972). The miniature linguistic system as a code-breaking device for the deaf. Dissertation Abstracts International, 33, 2790.

MacWhinney, B. (1983). Miniature linguistic systems as tests of the use of universal operating principles in second-language learning by children and adults. Journal of Psycholinguistic Research, 12(5), 467-478.

Matos, M. A., Avanzi, A. L. \& McIlvane, W. J. (2006). Rudimentary reading repertoires via stimulus equivalence and recombination of minimal units. The Analysis of Verbal Behavior, 22, 3-19.

Matos, M. A., Hübner, M. M. C. \& Peres, W. (1997). Oralização e cópia: efeitos sobre a aquisição de leitura generalizada recombinativa. Temas em Psicologia, 1, 47-65.

Matos, M. A., Hübner, M. M. C. \& Peres, W. (1999). Leitura generalizada: procedimentos e resultados. Em R. A. Banaco (Org.), Sobre Comportamento e Cognição: aspectos teóricos, metodológicos e de formação em análise do comportamento e terapia cognitivista, Vol. 1. (pp. 423-432). Santo André: ARBytes.

McIlvane, W. J. (1998). Teoria da coerência da topografia de controle de estímulos: uma breve introdução. Temas em Psicologia, 6, 185-189.

McIlvane, W. J. \& Dube, W. V. (1992). Stimulus control shaping and stimulus control topographies. Behavior Analyst, 15, 89-94.

Melchiori, L. E., de Souza, D. G. \& de Rose, J. C. (2000). Reading, equivalence, and recombination of units: A replication with students with different learning histories. Journal of Applied Behavior Analysis, 33, 97-100.

Miller, A. \& Ames, S. (1972). Extension of structural rules between miniature systems: Natural language versus artificial systems. Journal of General Psychology, 86(2), 163-171.

Mueller, M. M., Olmi, D. J. \& Saunders, K. J. (2000). Recombinative generalization of within syllable units in prereading children. Journal of Applied Behavior Analysis, 33, 515-531.

Nation, R. \& McLaughlin, B. (1986). Novices and experts: An information to the "good language learner" problem. Applied Psycholinguistics, 7(1), 41-55.

Negata, H. (1977). An experimental condition for creative aspects of morphemic use: Number of experienced exemplars. Psychologia: An International Journal of Psychology in the Orient, 20(2), 64-73.

Oliveira-Castro, J. M. (2000). Contingências programadas de reforço e complexidade discriminativa de tarefa: aplicações a situações de ensino. Em R. C. Wielenska (Org.), Sobre Comportamento e Cognição: Questionando e ampliando a teoria e as intervenções clínicas e em outros contextos V.6 (pp. 111-120). Santo André: Esetec.

Ray, B. A. \& Sidman, M. (1970). Reinforcement schedules and stimulus control. Em W. N. Schoenfeld (Org.), The theory of reinforcement schedules (pp. 187-214). New York: Appleton-Century-Crofts.

Rocha, A. M. (1996). Desenvolvimento de controle de estímulos por unidades menores que as utilizadas no treino: Efeito do tipo de variação nos elementos do estímulo complexo. Dissertação de Mestrado, Universidade de Brasília, Brasília. 
Saunders, K. J., O’Donnell, J., Vaidya, M. \& Williams, D. C. (2003). Recombinative generalization of within-syllable units in nonreading adults with mental retardation. Journal of Applied Behavior Analysis, 36, 95-99.

Sears, D. O. (1986). College sophomores in the laboratory. Influences of a narrow data base on social psychology's view of human nature. Journal of Personality and Social Psychology, 51, 515-530.

Sidman, M. (1971). Reading and auditory-visual equivalences. Journal of Speech and Hearing Research, 14, 5-13.

Sidman, M. (1994). Equivalence relations and behavior: A research story. Boston: Authors Cooperative.

Sidman, M. \& Tailby, W. (1982). Conditional discrimination vs. matching to sample: An expansion of the testing paradigm. Journal of the Experimental Analysis of Behavior, 37, 5-22.
Skinner, B. F. (1957). Verbal behavior. New York: Appleton. Smart, R. (1966). Subject selection bias in psychological research. Canadian Psychologist, 7, 115-121.

Wetherby, B. C. (1978). A functional analysis of miniature linguistic system learning in preschool children. Dissertation Abstracts International, 38, 6207-6208.

Recebido em 29.08.2006

Primeira decisão editorial em 05.02.2007

Versão final em 21.08.2007

Aceito em 25.09.2007 